\author{
EVS27 \\ Barcelona, Spain, November 17-20, 2013
}

\title{
Impact of electromobility on automotive architectures
}

\author{
Martin Luccarelli ${ }^{1}$, Dominik Matt ${ }^{2}$, Pasquale Russo Spena ${ }^{2}$ \\ ${ }^{l}$ Faculty of Design and Art, Free University of Bozen-Bolzano, piazza Università 1, Bolzano, Italy. \\ martin.luccarelli@unibz.it \\ ${ }^{2}$ Faculty of Science and Technology, Free University of Bozen-Bolzano, piazza Università 5, Bolzano, Italy
}

\begin{abstract}
The introduction of alternative powertrain technologies has brought increased design freedom in spaces within a vehicle that were previously constrained by traditional ones. Such freedom will affect the overall architecture and appearance of future alternative cars. However, these vehicles require the design, development, and integration of new specific components that are not relevant in conventional combustiondriven cars. This paper is a short review of challenges and methodological approaches regarding the design for changeability in future alternative vehicle production and design, and in particular, of methods coping with interchangeability. Modularity is seen as an appealing design approach that supports vehicle manufacturers for a wider spectrum of different interchangeable technologies, involving both production processes and products. The concepts of modularity in production, modularity in design, modularity in use, and technical modularity are here presented.
\end{abstract}

Keywords: BEV (battery electric vehicle), fuel cell, passenger car

\section{Introduction}

Alternative powertrain concepts will gain an increasing significance in the next 20 years. Although there is still a huge uncertainty regarding the future orientation of sustainable passenger mobility, optimistic scenarios have predicted that the market penetration of alternative vehicles will notably increase after around 2020, achieving about $80 \%$ market share [1]. By contrast, less optimistic foresights limit market penetration of these vehicles up to $35 \%$ by 2050 , and even less according to a Business-as-Usual scenario [1]. In the long run, battery electric vehicles and fuel cell vehicles will dominate the future automotive market scenario; however, the former will need more efficient fuel cells and hydrogen storage systems in order to gain a proper market share.
Despite all the efforts of car manufacturers, it is still a long way to get a mass production of fuel cell powered vehicles due to the high cost of fuel cell technologies. For this reason, different development scenarios have been also predicted for battery electric and fuel cell vehicles [2]: the establishment of a series production of fuel cell vehicles will start in the $\mathrm{D}$ segment and upper vehicle classes designed for fully-fledged longdistances, while battery electric vehicles will be mostly available for the A segment, as shown in Fig 1.

The introduction of alternative powertrain technologies has brought increased design freedom in spaces within a vehicle that were previously constrained by the traditional ones. Such freedom will affect the overall architecture and appearance of future alternative cars. On one hand, with design having a major influence on 
sales, car designs that meet customer's preferences are becoming more important [3].

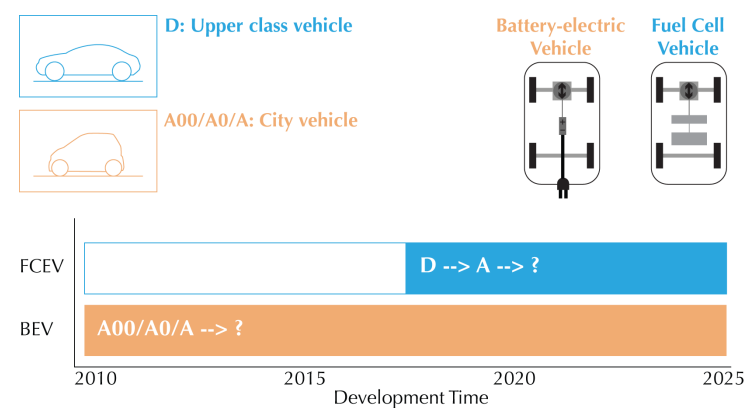

Figure 1: Assumption of a chronological scenario of electric vehicle concepts [2].

On the other hand, the new redistribution of volumes in the car allows designers to cope with the need of new compact design solutions to accommodate social and environmental changes such as ageing population, regional locations, and delivery businesses. Automotive industry is working on hybrid drive systems and has presented several electro-mobile concept cars, but a real breakthrough with a broad market penetration of alternative mobility solutions can be achieved only if today's production systems and value chain network can be adapted. Modularity, that is the ability of a system to be decomposed into a number of components that may be mixed and matched in a variety of configurations, appears to be a promising strategy in design and production of alternative vehicles, as well as supporting user customization during the use of the vehicle.

This paper is a short review of challenges and methodological approaches regarding the design for changeability in future alternative vehicle production and design, and in particular, of methods coping with interchangeability. Paragraph 2 examines two key issues concerning the impact of vehicle electrification on its overall architecture and production process: the integration of new specific components for a more flexible vehicle design and of new products on existing production systems. Paragraph 3 deals with concepts of modularity in production, modularity in design, modularity in use, and technical modularity to reach flexible automotive architectures. A visual conceptual model is presented to summarize these different types of modularity.

\section{Impact of electromobility on automotive design and production systems}

The design of present alternative fuelled vehicles mainly refers to mild forms of powertrain hybridization. Hybrid powertrains stand for vehicles with both a fossil and alternative fuelled power sources in the drivetrain. Such vehicles usually offer a parallel system with a start-stop device in combination with engine assist or regenerative braking features. Therefore, mild hybrid vehicles generally cannot run with electric propulsion only and powertrain is primarily based on traditional combustion engines. In the long run, instead, hybrid powertrain concepts with a larger share of electrification and batteryelectric vehicles will dominate the car market. Fuel cell vehicles will need drastic improvements in order to gain a notable market share [1]. The transition from traditional to alternative vehicle will not only concern driven powertrain, but also car architecture. In such sense, analysing present commercial vehicles and innovative concept cars, it can be assumed that alternative vehicle will undergo a drastic change in architecture in the next future. In traditional vehicle, the combustion engine area, the passenger area, and the luggage area were clearly divided the one from the other. This did not allow volume redistribution between passengers and luggage areas when needed by users. As far as the future short-term is concerned, hybrids will dominate the market. These vehicles are quite similar to traditional ones, thus, although they might offer a higher degree of flexibility in space usage, a large area is still needed to fit the two powertrain systems. In the long-term scenario, fuel cell and battery electric vehicles could allow to gain a high level of flexibility through high-end drive-by-wire technologies. Specifically designed software will replace the traditional mechanical operating systems, controlling the vehicle by means of electromechanical actuators and human-machine interfaces [4]. Hence, traditional components such as intermediate shafts, master cylinders, pumps, hoses, belts, coolers and vacuum servos, and steering column will be eliminated, and a new volume distribution within the vehicle is obtained. Alternative vehicles require the design, development, and integration of new specific components that were not relevant in conventional combustion-driven cars. However the production of these components has to be fitted into production systems used for traditional 
vehicles. If electric cars are produced in small number, the most economical process to produce them is to convert existing conventional cars. This conversion usually includes the removal of the internal combustion engine and its supporting subsystems, and their replacement with an electric motor (and controller) and a battery with enough capacity to guarantee a reasonable driving range. An example of traditional-to-electric vehicle conversion is the Testla Roadster (released in 2006) that is basically a Lotus Elise model with an electric drivetrain. In addition to the simple conversion from conventional vehicles, Cuenca et al. [5] listed two other possible production approaches that can be used for the fabrication of electric vehicles in a larger scale: an all new original equipment manufacturer (OEM) production and glider conversion. The first method, a direct OEM production, can be intended as a modification of an existing model or as a new "ground-up" design. Electric vehicles can be assembled in the same plant as their conventional counterparts, although not necessarily on the same assembly line. A new design will most likely need an all-new assembly plant at higher costs. The second method, the glider conversion, refers to a modular production method where a basic chassis is built and assembled with certain components (creating the glider), including all the standard ones that are usable by both conventional vehicles and electric vehicles. For example, a platform can include suspensions, wire harnesses, instrument panels, HVAC (Heating, Ventilation, and Air Conditioning) components, and brackets. Such a platform would only need the assembly of electric traction and energy storage components in the case of electric cars, or combustion engines and accessories in conventional ones. In this way, a low-cost production could be obtained by using an existing conventional vehicle platform as base. Of course, vehicles produced by these three processes (conversion, direct OEM production, and glider conversion) will be not equivalent and their adoption is strictly related to production volumes. The simple conversion from conventional vehicles turns out to be competitive in a short run and only for a small production (100 - 400 units/yr.). An original design allows higher optimized lightweight body design at higher costs. A complete transformation of established production systems would be required to produce these cars. That can be only justified for higher production volumes (5.000 - 40.000 units/yr.). Finally, electric vehicles produced on existing traditional vehicle platforms may turn out to be less innovative in the short run from a product point of view. Vehicles produced via this production method may risk a loss of innovation in their architectural design due to the need of standardization among the different models produced. However, this method might guarantee more flexibility for modest volumes (500 - 4.000 units/yr.) and, hence, it might turn out to be more competitive as well, as the future of large-scale alternative vehicles production remains uncertain.

\subsection{Optimizing the integration of new specific components}

Today a large share of vehicle components is integrated into families, called systems and modules. These are supplied to vehicle manufacturers as complete functional units to speed up automotive assembly process [6-7]. Sturgeon et al. [6] have identified the most important modules for the fabrication of conventional vehicles: engines (including transmission, and axles), suspensions, doors, headliners (including components such as grip handles, lighting, wiring, sunroof, sun visors, and trim preassembled), ventilation (including heating and air-con units), seats, and dashboard. Comparing alternative powertrain concepts can be an appealing approach to identify the components that can be shared in various drivetrain solutions, and, hence, to verify if the components of alternative vehicles might be integrated in traditional production process lines and fitted in different products. Christensen [8] chose three alternative vehicle solutions to do this type of comparison: fuel cell, plug-in hybrid, and battery electric drivetrains. Stop-start device, plug-in hybrid drive train, fuel cell drivetrain, and battery electric drivetrain were identified as all based on some kind of electric application. Thus, batteries, electric motors, inverters, generators, brake energy regeneration systems, and other electric components could be shared among the examined drivetrain options. Fuchs et al. [2] made a comparison between fuel cell and battery electric drivetrain. In this case, three main components were identified as key concept defining features: electric drive train system, traction battery system, and high-voltage supply, as shown in Fig. 2.

Surely, the battery is the main shared component that can be identified in any alternative drivetrain technology. It is essential for a number of reasons including price, weight, and performance of a vehicle. 


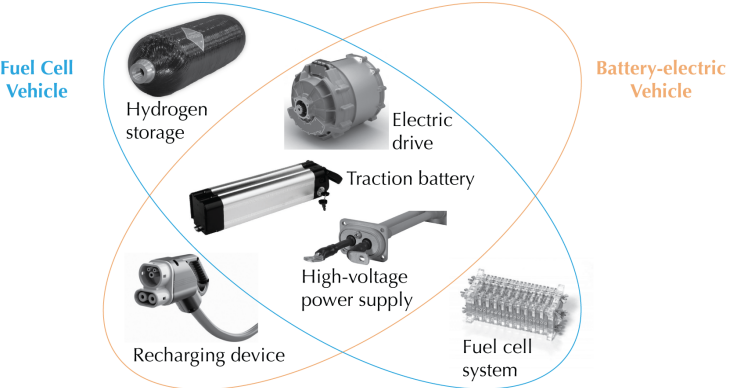

Figure 2: Concept-defining components for FCEV and BEV [2].

However, it must be pointed out that battery is also the main technical bottleneck in the usage of an alternative drivetrain. In fact, energy storage capacity of today's batteries is less than the energy density of gasoline and diesel by a factor of 50 and more (about 0,2 kWh/kg vs. more than $10 \mathrm{kWh} / \mathrm{kg}$, respectively). Two ways can be pursued in order to overcome this storage problem. The former is the development of alternative sources to lithium ion batteries [9] and the optimization of their integration in car chassis. The Testla $\mathrm{S}$ model is a good example in this sense; the batteries are placed on the bottom of the chassis, thus obtaining nearly the same weight distribution on both the front and the rear axles, a remarkably low centre of gravity, and, hence, a rigid body structure. The other way is the adaptation of vehicle architecture to allow a direct battery exchange service. Renault has adapted its plug-in hybrid sedan model Fluence Z.E. to enable battery switching in special battery swapping stations. In these stations, the battery is switched from the bottom of the car by an automatic system. In 2012, 24 battery swapping stations worked in Israel and 12 in Denmark, and they served more than 750 customers [10]. Fuel cell vehicles try to overcome the problem of recharging by powering their on-board electric motor using hydrogen and atmospheric oxygen as reaction media (proton exchange membrane). At the moment, only few fuel cell cars are available on the market and are usually conversions of conventional cars; the Mercedes B class F Cell and the Chevrolet Equinox Fuel Cell count as examples. So far, the only vehicle that has been specifically assembled around a fuel-cell engine is the Honda FCX Clarity. A visible impact of this powertrain system on the automotive architecture is the bulky fuel tank needed to run the vehicle. In fact, the volume of the tank in which the hydrogen is stored needs to be at least four times that of a full tank of gasoline for an equivalent distance of travel [11].
According to Fuchs et al. [2], understanding how electric components influence the overall vehicle package is a key issue in the design of perspective electric vehicle concepts. Starting from a chosen reference concept, simulations can be done by varying installation space and properties of electric components. Impacts of the overall system weight, volume, cost, and energy consumption can be then analysed. The objective is to design efficient packaging for specific components (such as high-voltage batteries, electric drivetrains, fuel cell, and hydrogen storage systems) and to develop suitable functional design that is coherent with complete vehicle concepts.

\subsection{Integrating new products on existing production systems}

As already mentioned, forecasts and scenarios differ widely between battery electric and fuel cell vehicles. Therefore, the biggest challenge for automotive production, due to the electrification of the powertrain, is to forecast which alternative drive concept will prevail and in what volumes. Christensen [8] argued that the essential question regarding the future of alternative drive train solutions is whether they can be fitted into conventional production systems or necessitate a complete transformation. According to Lovins et al. [12], the full potential of alternative drivetrains is unexploited unless vehicles are reinvented completely. Designing components and subsystems independently, as it is the case of modularised production systems, would not cope with this objective. The downside is that such a design strategy (a new "ground-up" design direct OEM production) would require a complete transformation of established production systems. Huge sunk costs of production equipment, designed for production of steel based cars fitted with combustion engines, makes such a transformation improbable. Hence, the reusing of production equipment appears as the key issue to integrate alternative vehicles into traditional production lines. The introduction of vehicle platforms has already proved the ability to assemble more models in the same assembly line; however, there is still a lot of room for improvement with reference to mass customisation.

Some trends are influencing negatively the ramp up of technologies and processes in the automotive industry. Walla et al. [13] pointed out that the model cycle in automotive industry has decreased from 10 to 6 years during the last 
decades. For this reason, the lifetime of production systems is often longer than product life cycle of products manufactured. In addition, the demand for individualized and configurable cars, new materials integration in automotive vehicles, and the related processing technologies have increased [14]. Fig. 3 shows the life cycle of a production system for the body-in-white production.

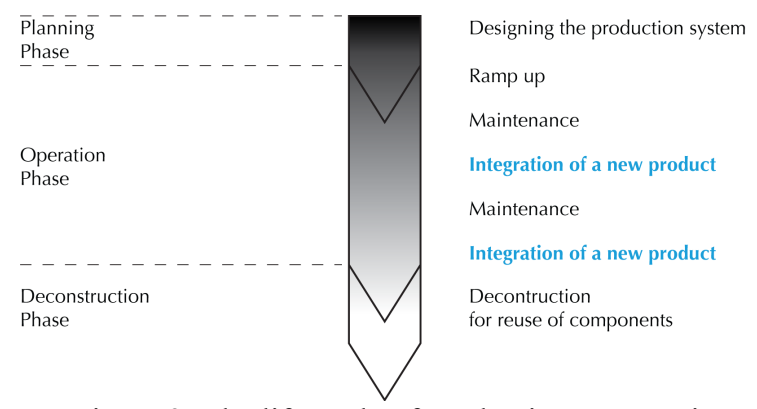

Figure 3: The life cycle of production systems in automotive manufacturing [13].

As the single product variants come into the market at different times, an integration process of new products is necessary several times during the whole life cycle of the production system. Digital tools for validation are usually used in order to guarantee a smooth integration process and a better collaboration between product designers and production planners [13]. Nevertheless, there is still a lack of flexibility between the different factory departments involved to handle product variety.

\section{Engineering methods coping with interchangeability}

The drastic change expected for future alternative vehicle architectures has to be supported by production engineering methods that increase changeability in the process. Spath et al. [15] focused on production and consider modularity as one of the three main principles for changeability (modularity, universality and compatibility). However, productivity can be enhanced only if both product design and production methods are redesigned as a whole system [14]. To redesign the whole system effectively, three modular principles were introduced by Sako et al. [16]: modularity in design (MID), modularity in production (MIP), and modularity in use (MIU). In MID, modularization is focused on boundaries between sub-systems of integrated components in design features and tasks. The partition of a product into smaller parts (modules), allows them to be created independently and then used in different systems to drive multiple functionalities. The modularity in the design of vehicles refers to the interchangeability of certain modules of a passenger car and their broader usage in different car types independent from the applied powertrain concept. Moreover it can refer to a certain component that can be added or removed without altering the rest of the car. This module independence allows an incremental innovation within each module without affecting the overall vehicle architecture, coping with the uncertainties regarding the future of alternative vehicles. Among the three principles of modularity, MID is the key for future modular vehicles: "much of a production system's ability to create variety resides not with the flexibility of the equipment in the factory, but with the architecture of the product" [17]. MIP concerns the interchangeability and degree of sharing of functional sub-systems of integrated components across product variants. To share as much subsystems as possible, it is important to precombine a large number of components into modules and to assemble them off-line. According to Persson [18], MIP should be introduced in automotive production for three reasons: lower cost, more flexibility, and less task complexity. Lower costs, as the partition of a product into independent and interchangeable functional units allows manufacturers to increase product variety by enabling large-scale production of relatively customised products. More flexibility, as MIP enables manufacturers to respond to changing market requirements by re-using modules across models or model generations. Less task complexity, as MIP enables different parts of a given product to be developed and produced in parallel tracks, as long as the standard interface between the various modules is maintained. As well known, design method coping with MIP is known as platform design: to reuse a single platform across more vehicle models to reduce development times and costs [19]. MIU comprises the product boundaries and interchangeability of elements relevant to customers on the end-market. A set of options allows the customer to personalize the product to suit its individual needs and tastes, an issue strictly connected to mass customization [20]. In automotive industry this last type of modularization is often seen as a consumer only driven decomposition of car. For this reason, Morris et al. [21] consider only MID and MIP as key modular features for automotive industry. However, Batchelor [22] considers MIU 
important as well, as it involves the maintenance of the product and, hence, it involves both users and manufacturers in the whole process.

Considering the redistribution of volumes in the architecture of alternative vehicles, MID supports innovative ways to customize cars. In the future, ordinary systems like the three-box design concept (engine, passenger, and cargo), the two-box design concept (station wagon configuration) or the more recent one-box design concept (mono-volume configuration) could evolve to interchangeable architectures according to user's needs. The GM fuel-cell concept vehicle AUTOnomy (2002) is one of the best examples of interchangeable architecture. With the use of a skateboard concept, future users could modify their own car by simply replacing another car-body on the chassis thanks to drive-by-wire technology. Although a conceptual skateboard design is still far from reality, more recent car concepts have proven that enabling new connectivity developments to be continually integrated within existing chassis will be a trend in future automotive design [23].

From an organisational point of view, MID reduces complexity as result of design interdependence, MIP increments manufacture flexibility by taking complex tasks off the main assembly line, and MIU increases product variety by offering more choices to user. From a product point of view, MID represents the functional decomposition of it, MIP is the process decomposition of the product, while MIU stands for its physical decomposition. The ensemble of these three types of modularity is known as technical modularity, as they are primarily related to the technical configuration of vehicle design (design, production, and use) [8]. Therefore, technical modularity can be reached only if all the three types of modularization are fulfilled in the engineering process.

\subsection{Visualization of technical modularity features through conceptual model}

In order to sum up and visualize better the abovementioned modular features in present automotive engineering, a conceptual model is presented in this section. All the three principles of modularity
(MID, MIP, and MIU) were considered to display technical modularity. The following assumptions were made for the design of the conceptual model:

1. powertrain system and battery will be placed as low as possible in the chassis (hence, long wheelbase), allowing a rigid body structure, an optimal weight distribution, and the lowest centre of gravity reachable;

2. luggage area and passenger area should occupy the maximum space available in the car and should be flexible for high customization;

3 . future architectures will grow in the vertical axis rather than in the horizontal axis (hence, short overhangs), coping with the need of compact design solutions. An in-wheel assembled electric engine was considered for the functional decomposition of the conceptual model (MID). This engine could be applied to both battery electric vehicle concepts and fuel cell electric vehicle concepts. The inverters are stored on the car axels in order to reach a low positioned chassis-area to accommodate the batteries. Fig. 5 (1) shows the different components of the modular designed model. As far as the interchangeability and degree of sharing of functional sub-systems of integrated components across vehicle models is concerned (MIP), the chassis is ready to accommodate the different car-bodies once the key elements are fitted. Assuming the adoption of an adaptable chassis, platform dimensions could grow according to the performance needed from the traction battery system and the overall dimensions of the car, as shown in Fig. 5 (2). Three architecture types were considered to display the principle of modularity in use (MIU): - a small pick-up truck for delivery businesses in regional locations;

- a family car with extra height to accommodate social changes such as ageing population;

- a limousine with a silhouette designed in accordance with the results of Reid et al. on the perceived environmental friendliness in automotive design [24].

Assuming that end users will need different car models to fulfil the needs of their everyday life, future drivers could modify their own car by 

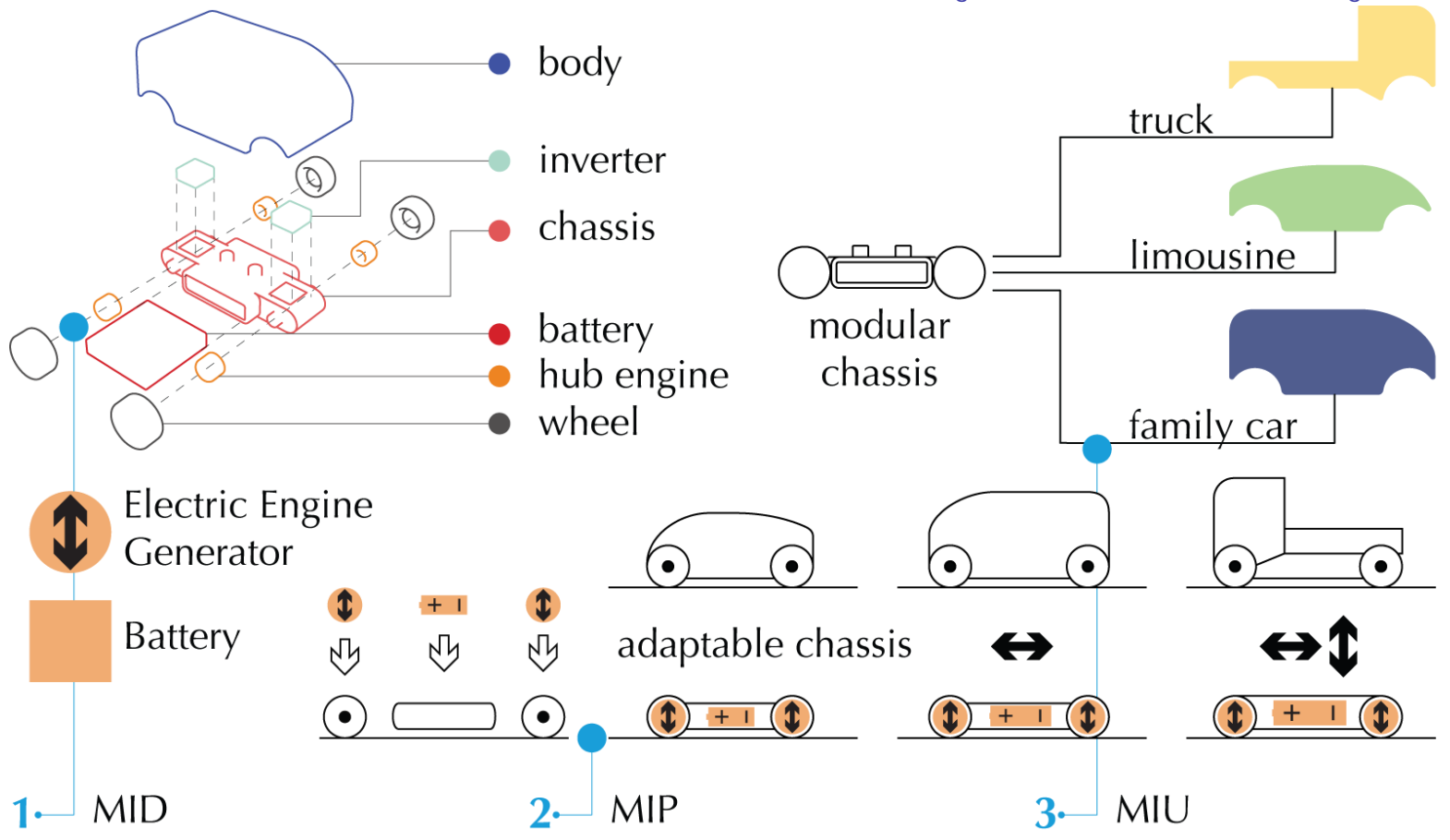

Figure 4: Model displaying the principles of technical modularity.

simply replacing another car-body on the chassis thanks to the drive-by-wire technology. This future trend could be compared with the present habit of changing from summer to winter tires. Special designed car body-swapping stations like the battery-swapping stations for electric cars [10] could serve as storage system for users. Fig. 5 (3) shows the three body types.

\section{Conclusions}

This paper has investigated challenges and methodological approaches regarding the design for changeability in future automotive production, and in particular, methods coping with interchangeability. Modularity is seen as an appealing design approach that supports vehicle manufacturers for a wider spectrum of different interchangeable technologies and involves both production processes and products.

Vehicle manufacturers involved in designing alternative powertrains may therefore be able to reuse components and systems. Not only the battery, which is essential for price of the system, weight, and vehicle performance, but also electric drive train system, and high-voltage supply. These three key components are concept-defining features for the fuel cell and battery electric drivetrain that should dominate the future alternative automotive market scenario.

The technical linkages between these two alternative drivetrains additionally allow vehicle manufacturers to benefit from technological discoveries made in competing drivetrains. In fact, based on the high cost of fuel cell concepts, it is assumed that battery electric vehicles and fuel cell vehicles will establish in different vehicle segments.

Automotive manufacturers have not set real breakthrough modular architecture vehicle concepts into production so far. The auto industry perspective on the future of electric cars could be the adoption of advanced modular systems that involve all the three types of modularization: modularity in design, modularity in production, and modularity in use. The conceptual model highlighted a variety of future opportunities for designers, manufactures and end users that such a system could offer through function, production process, and physical decomposition of the product.

\section{References}

[1] Ciarapica, F.E., Matt, D.T., Luccarelli, M., Rossini, M. \& Russo Spena, P., 2013. Factors Affecting Future Scenarios for Alternative Vehicles Market. Advanced Materials Research, 608 - 609, 1607-1612.

[2] Fuchs, J., Huber, R., Lienkamp, M. \& Riemenschneider, T., 2013. Impact of Electrification on the Vehicle Concept Potential of Determining Components and Technologies. In Conference on Future Automotive Technology. Springer Fachmedien Wiesbaden, 119-146.

[3] Landwehr, J.R., Labroo, A.A. \& Herrmann, A., 2011. Gut Liking for the Ordinary: Incorporating Design Fluency Improves Automobile Sales Forecasts, Marketing Science, 30 (3), 416-429. 
[4] Lukasiewycz, M., Steinhorst, S., Andalam, S., Sagstetter, F., Waszecki, P., Chang, W., Kauer M., Mundhenk P., Shanker S., Fahmy S. A., Chakraborty S., 2013. System architecture and software design for electric vehicles, Proceedings of the 50th Annual Design Automation Conference, Austin, Texas: ACM, 1-6.

[5] Cuenca, R.M., Gaines, L.L. \& Vyas, A.D., 2000. Evaluation of electric vehicle production and operating costs, Center for Transportation Research, Energy Systems Division, Argonne National Laboratory, Illinois.

[6] Sturgeon, T. \& Lester, R.K., 2004. The New Global Supply Base: New Challenges for Local Suppliers in East Asia, In Yusuf, S., Altaf, M., A. \& Nabeshima, K. eds. Global Production Networking and Technological Change in East Asia. World Bank Publication.

[7] Pandremenos, J., Paralikas, J., Salonitis, K. \& Chryssolouris, G., 2009. Modularity concepts for the automotive industry: A critical review, CIRP Journal of Production Science and Technology, 1 (3), 148-152.

[8] Christensen, T.B., 2011. Modularised ecoinnovation in the auto industry, Journal of Cleaner Production, 19 (2-3), 212-220.

[9] Hueso, K.B., Armand, M. \& Rojo, T., 2013. High temperature sodium batteries: status, challenges and future trends, Energy \& Environmental Science, 6 (3), 734-749.

[10] Berman, B., McDonald, Z. 2012. Chief steps down at a company serving electric cars, The new york times, 2 October.

[11] Kaiser, O.S., Eickenbusch, H., Grimm, V. \& Zweck, A., 2008. The future of the car, Zukünftige Technologien Consulting of VDI Technologiezentrum GmbH.

[12] Lovins, A.B. \& Cramer, D.R., 2004. Hypercars, hydrogen, and the automotive transition, International Journal of Vehicle Design, 35 (1), 50-85.

[13] Walla, W. \& Kiefer, J., 2011. Life Cycle Engineering-Integration of New Products on Existing Production Systems in Automotive Industry, Glocalized Solutions for Sustainability in Production, 207-212.

[14] Minhas, S.U.H., Lehmann, C. \& Berger, U., 2011. Concept and Development of Intelligent Production Control to enable Versatile Production in the Automotive Factories of the Future, in Hesselbach, J. \& Herrmann, C. eds. Glocalized Solutions for Sustainability in
Production. Springer Berlin Heidelberg, 5762.

[15] Spath, D., Rothfuss, F. \& Sachs, C., 2010. Hybride Produktionssysteme - Integration elektromobiler Antriebskonzepte in automobile Produktionssysteme, in: Nyhuis, P., ed.^eds. Wandlungsfähige Produktionssysteme - Schriftenreihe der Hochschulgruppe für Arbeitsund Betriebsorganisation eV (HAB), Hannover: GITO - Verlag GmbH 261 - 280.

[16] Sako, M., \& Murray, F., 1999. Modules in design, production and use: implications for the global auto industry, Paper presented at the IMVP Annual Sponsors Meeting.

[17] Ulrich, K., 1995. The role of product architecture in the production firm, Research policy, 24(3), p.428.

[18] Persson, M., 2006. Editorial Introduction, International Journal of Automotive Technology and Management, 6 (3).

[19] Siddique, Z., Rosen, D. W., \& Wang, N., 1998. On the applicability of product variety design concepts to automotive platform commonality, Paper presented at the Proceedings of DETC98.

[20] B Joseph Pine, I., Davis, S., 1999. Mass customization: the new frontier in business competition, Harvard Business School Press.

[21] Morris, D. \& Donnelly, T., 2006. Are there market limits to modularisation? International Journal of Automotive Technology and Management, 6 (3), 262275.

[22] Batchelor, J., 2006. Modularisation and the changing nature of automotive design capabilities, International journal of automotive technology and management, 6 (3), 276-297.

[23] Becker, D., 2012. Will the vehicle of the future be available in modules? Kpmg.

[24] Reid, T.N., Frischknecht, B.D. \& Papalambros, P.Y., 2012. Perceptual Attributes in Product Design: Fuel Economy and Silhouette-Based Perceived Environmental Friendliness Tradeoffs in Automotive Vehicle Design, Journal of mechanical design, 134 (4). 